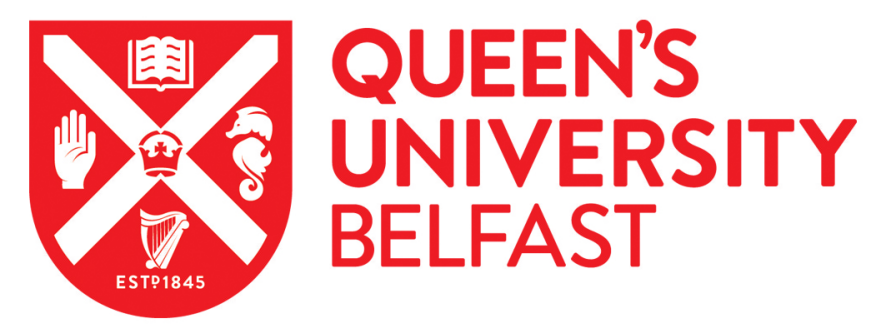

\title{
Tetrodotoxin detection in puffer fish by a sensitive planar waveguide immunosensor
}

Reverte Calvet, L., Campàs, M., Yakes, B. J., Deeds, J. R., Katikou, P., Kawatsu, K., Lochhead, M., Elliott, C. T., \& Campbell, K. (2017). Tetrodotoxin detection in puffer fish by a sensitive planar waveguide immunosensor. SENSORS AND ACTUATORS B-CHEMICAL, 253, 967-976. https://doi.org/10.1016/j.snb.2017.06.181

\author{
Published in: \\ SENSORS AND ACTUATORS B-CHEMICAL
}

\section{Document Version:}

Peer reviewed version

\section{Queen's University Belfast - Research Portal:}

Link to publication record in Queen's University Belfast Research Portal

\section{Publisher rights}

(C) 2017 Elsevier Ltd.

This manuscript is distributed under a Creative Commons Attribution-NonCommercial-NoDerivs License

(https://creativecommons.org/licenses/by-nc-nd/4.0/), which permits distribution and reproduction for non-commercial purposes, provided the author and source are cited.

\section{General rights}

Copyright for the publications made accessible via the Queen's University Belfast Research Portal is retained by the author(s) and / or other copyright owners and it is a condition of accessing these publications that users recognise and abide by the legal requirements associated with these rights.

Take down policy

The Research Portal is Queen's institutional repository that provides access to Queen's research output. Every effort has been made to ensure that content in the Research Portal does not infringe any person's rights, or applicable UK laws. If you discover content in the Research Portal that you believe breaches copyright or violates any law, please contact openaccess@qub.ac.uk. 


\section{Tetrodotoxin Detection in Puffer Fish by a Sensitive Planar Waveguide Immunosensor}

Laia Reverté ${ }^{a, b}$, Mònica Campàs ${ }^{b}$, Betsy Jean Yakes ${ }^{c}$, Jonathan R. Deeds ${ }^{c}$, Panagiota Katikou $^{d}$, Kentaro Kawatsu ${ }^{\mathrm{e}}$, Michael Lochhead ${ }^{\dagger}$, Christopher T. Elliott ${ }^{\mathrm{a}}$ and Katrina Campbella*

a Institute for Global Food Security, School of Biological Sciences, Queen's University, David Keir Building, Stranmillis Road, Belfast, UK BT9 5AG.

b IRTA, Ctra. Poble Nou, km 5.5, Sant Carles de la Ràpita, Spain.

c US Food and Drug Administration, Center for Food Safety and Applied Nutrition (CFSAN), 5001 Campus Drive, College Park, MD 20740, USA.

d National Reference Laboratory on Marine Biotoxins, Ministry of Rural Development and Food, 54627 Thessaloniki, Greece.

e Division of Bacteriology, Osaka Prefectural Institute of Public Health, 3-69, Nakamichi 1chome, Higashinari-ku, Osaka 537-0025, Japan.

${ }^{f}$ MBio Diagnostics Inc., 5603 Arapahoe Avenue, Boulder, Colorado 80303, USA.

Footnote: Laia Revertéa,b, PhD student at IRTA, conducted this work as Visiting Researcher at QUB.

Corresponding Author

Dr Katrina Campbell

Institute for Global Food Security,

School of Biological Sciences,

Queen's University,

David Keir Building,

Stranmillis Road,

Belfast, UK

BT9 5AG.

E-mail: katrina.campbell@qub.ac.uk 


\section{Abstract}

A nanoarray planar waveguide biosensor was developed for the detection of tetrodotoxin (TTX). This technique, specifically designed for the first time for TTX, provided a compact versatile user friendly device that obtained a test result in ten minutes. The device consisted of nanoprinted toxin-conjugate arrays constructed in the manner of an indirect competitive immunoassay, for the analysis of puffer fish samples under high flow conditions. The applicability to natural samples was investigated through the study of matrix effects and toxin recovery. The biosensor enabled the detection of TTX from 0.4 to $3.29 \mu \mathrm{g} \mathrm{g}^{-1}$ puffer fish tissue. The sensitivity attained demonstrates this assay as a rapid and sensitive screening method to detect TTX in different species of puffer fish, well below the Japanese maximum permitted level $\left(2 \mu \mathrm{g} \mathrm{g}^{-1}\right)$ and the estimated safety level used in the EU and the US (0.8 $\mu \mathrm{g}$ $\left.\mathrm{g}^{-1}\right)$. Assay repeatability and reproducibility were assessed at 0.4 and $0.8 \mu \mathrm{g} \mathrm{g}^{-1}$, showing relative standard deviation (RSD) values below $15 \%$ and toxin recovery within $85-115 \%$. The appropriate correlation of data obtained from the biosensor compared to that reported by ELISA, RBA, SPR biosensor and LC-MS/MS for the analysis of 12 puffer fish samples, proved the feasibility and reliability of this immunosensor to support monitoring programs and research activities.

Keywords: nanoarray; planar waveguide immunosensor; tetrodotoxin; puffer fish 


\section{Introduction}

Tetrodotoxin (TTX) is one of the most hazardous low-molecular-weight marine neurotoxins [1], whereby poisoning following consumption has a notorious lethal incidence. TTX is commonly found in the organs of select puffer fish species, typically the liver, ovaries, and gastrointestinal (GI) tract but also occasionally in the meat. TTX is also found in other organisms, and this toxin is believed to be exogenously produced, starting from bacteria which accumulate up through the food chain into fish, bivalve shellfish, amphibians and octopus [2]. Human fatalities from Puffer Fish Poisoning (PFP) are mostly caused by the ingestion of puffer fish ("fugu") in Japan [3], but the presence of TTX has also been reported in bivalve shellfish, harvested in several parts of Europe [4-6] and other countries [7, 8]. The main symptoms of PFP range from neuromuscular (lips and tongue paraesthesia, tingling and numbness) to gastrointestinal (nausea, abdominal pain, vomiting and diarrhea) [9]. More severe symptoms consist of uncoordinated movements, muscle spasms, and progressive muscle paralysis that can result in respiratory failure in severe intoxication cases. TTX toxicity (LD50) is $2-10 \mu \mathrm{g} \mathrm{kg}^{-1}$ intravenously and $10-14 \mu \mathrm{g} \mathrm{kg}^{-1}$ subcutaneously in mammals as well as $334 \mu \mathrm{g} \mathrm{kg}^{-1}$ orally in mice [10].

TTX and its related analogues are hydrophilic, heat-stable, heterocyclic compounds [11, 12], able to selectively block sodium channels $[13,14]$. To date, 29 analogues of TTX have been described, which when classified according to their structure are: hemylactal, lactone and 4,9 anhydro types. To the best of our knowledge, little is known about the role that these analogues may play in terms of toxicity, with the exception of the study performed by YotsuYamashita and co-workers in rat membranes where 5,6,1-trideoxy TTX showed less toxicity than other analogues [15]. To protect consumers against PFP in Japan, the regulatory limit for TTX in food is $2 \mu \mathrm{g}$ TTX equivalents $\mathrm{g}^{-1}$ [16]. In the US, no guidance level has been established, and TTX intoxications from puffer fish are predominantly limited through importation restrictions which only allow the puffer fish species Takifugu rubripes from Japan 
to be brought into the country with additional strict processing guidelines [17]. All other imported puffer fish products are subject to automatic detention without physical examination by the US Food and Drug Administration (FDA) [18]. Despite these strict import restrictions, several cases of PFP have been reported in recent years in the US due to the unapproved importation of puffer species [19, 20]. Additionally, no regulatory limits have been specifically set for TTX in Europe. However, in both Europe and the US, safety limits have been set at $0.8 \mu \mathrm{g}$ saxitoxin (STX) equivalents $\mathrm{g}^{-1}$ shellfish meat for the pharmacologically similar paralytic shellfish poisoning (PSP) toxins. This concentration can be used as a guide in determining the role of TTX in incidents of illness. The increasing incidence of seafood TTX poisoning episodes in Europe and in other non-regulated regions might have relevant consequences to food safety and economic fisheries. Therefore, there is a real need for the development of methods suitable to regulate this toxin in food by means of routine monitoring, thus, providing sufficient protection to human health and fishery products [21].

In Europe, the shift for PSP toxins screening in bivalves and seafood from the mouse bioassay (MBA) which inadvertently detected TTX toxins, to the method of Lawrence using high-performance liquid chromatography with fluorescence detector (HPLC-FLD) [22], created a gap in the detection for other important paralytic toxins such as TTX that are relevant to food safety and that are not detected by the latter technique. Current methods for TTX detection are mainly those based on analytical chemistry, such as HPLC and liquid chromatography tandem-mass spectrometry (LC-MS/MS) [23]. Although useful techniques, their performance is occasionally hampered by the lack of commercially available analytical standards for some TTX analogues and by the requirement of skilled personnel and expensive equipment. TTX detection has also been achieved by biochemical methods, including immunoassays [24-30] and electrochemical [25, 31] and optical immunosensors [32-37], some of these having shown promise not only as research activities but also as 
screening tools in monitoring programs. Biosensors are increasingly being investigated due to the advantages they offer in terms of sensitivity, portability, ease of use and robustness. To date, surface plasmon resonance (SPR) immunoassay has been the most widely applied biosensor-based method for TTX, though the cost of instrumentation has prevented this method's broader uptake. More recently, another optical biosensor, based on planar waveguide technology, is gaining attention, and it has been successfully developed for other marine toxins, such as okadaic acid (OA), domoic acid (DA) and saxitoxin (STX) [38], but not yet explored for TTX detection. Accordingly, an immunosensor based on the planar waveguide technology with fluorescence detection for the determination of TTX is described herein. In this technique, waveguide cartridges are previously spotted with picoliter drops of the desired toxin-conjugate, and the extent of the molecular interaction upon addition of the antibody is determined through a fluorescence reader. In the assay, when toxin is not present in a sample, nearly all the primary antibody is bound to the toxin conjugate attached on the surface, and a high fluorescence signal is obtained from the secondary antibody. When toxin is present in the sample, the antibody binds to this toxin in solution, thereby decreasing the amount of primary antibody available to bind to the surface and thus the fluorescence signal decreases proportionally to the toxin concentration. The signal itself is generated from light that is transmitted from the bottom of the waveguide cartridges, leading to the excitation of the fluorophores on the labeled-secondary antibody, thus enabling the sensitive recording of binding events on the surface (Figure 1). The aim of this work was to investigate this planar waveguide biosensor for the rapid detection of TTX in puffer fish samples using a simple extraction method. After development, this biosensor was applied to the analysis of samples, and the results were compared to other methods of analysis including the MBA, receptor binding assay (RBA), ELISA, SPR biosensor and LC-MS/MS analysis. 


\section{Material and methods}

\subsection{Reagents}

Bovine serum albumin (BSA), casein from bovine milk, phosphate buffered saline (PBS) tablets, sodium acetate anhydrous, sodium chloride, sodium phosphate dibasic, sodium phosphate monobasic and Tween 20 were purchased from Sigma-Aldrich (Dorset, UK). Alexa Flour 647 goat anti-mouse IgG (GaM) antibody and BSA-Alexa Fluor 647 conjugate were obtained from Invitrogen Ltd. (Paisley, Scotland). TTX standard was procured from Biomol/Affiniti Research Products (Exeter, UK).

\subsection{Sample collection}

Seven puffer fish samples (Lessepsian migrant puffer fish Lagocephalus sceleratus) were obtained from the National Reference Laboratory for Marine Biotoxins (NRLMB) of Greece. Five puffer fish muscle samples (Lagocephalus lunaris), which were previously associated with several outbreaks of illness in the US in 2007 [19], were from collaborators at the FDA. TTX-free puffer fish muscle from Takifugu rubripes was also provided by FDA and used as negative tissue for matrix effects and toxin recovery experiments.

\subsection{Sample extraction method}

The extraction method used was previously described by Bates and co-workers [39] for the SPR analysis of PSP toxins in shellfish [40]. Briefly, $1 \mathrm{~g}$ portions of puffer fish homogenate were weighed into $20-\mathrm{mL}$ disposable Sterilin centrifuge tubes, and $4 \mathrm{~mL}$ of sodium acetate buffer pH 5.0 was added. Each tube was vigorously vortex mixed for $10 \mathrm{~s}$ followed by roller mixing (STUART SRT9, Bibby Scientific Ltd, UK) at 33 rpm for $30 \mathrm{~min}$. After mixing, samples were centrifuged at 3,600×g (SORVALL Legend RT, DJB Labcare Ltd, UK) for 10 min at room temperature. The supernatant was decanted, collected, and 40-fold diluted in MBio 
assay buffer at $\mathrm{pH} 7.4$ (25 $\mu \mathrm{L}$ extract to $975 \mu \mathrm{L}$ buffer). MBio assay buffer consisted of $1 \%$ BSA, $0.05 \%$ Tween 20 , one PBS tablet and $200 \mathrm{~mL}$ of distilled water.

\subsection{Synthesis of the immunological reagents}

TTX conjugate, TTX-jeffamine-keyhole limpet hemocyanin (TTX-jeff-KLH), was produced by combining different methods and with some modifications [24, 41-44]. In brief, jeffamine was conjugated initially to $\mathrm{KLH}$ via amine coupling in the same manner as that previously described for BSA [41]. One $\mathrm{mg}$ of TTX and $50 \mu \mathrm{L}$ of $37 \%$ formaldehyde were then added to $5 \mathrm{mg}$ of jeff-KLH protein. This mixture was allowed to react for $72 \mathrm{~h}$ at room temperature followed by dialysis in $0.15 \mathrm{M}$ saline solution $(3 \times 4 \mathrm{~L}$ ) over $24 \mathrm{~h}$. The production of monoclonal antibody against TTX (mAb) was previously described [24]. Moreover, the mAb has been further characterized and used in published works [27, 40].

\subsection{Cartridge spotting and standardized building process}

Microarrays were printed using a sciFLEXARRAYER S5 spotter (Scienion, Germany) equipped with a Bio-Jet print head capable of dispensing 25-nL droplets with spot diameters of approximately $0.5 \mathrm{~mm}$ on the slides in a $2 \times 22$-array format. TTX conjugate diluted in sterile filtered printing buffer (100 mM sodium phosphate, $50 \mathrm{mM}$ sodium chloride, $100 \mu \mathrm{g}$ $\mathrm{mL}^{-1}$ BSA, $0.005 \%$ Tween $\left.20, \mathrm{pH} 8.0\right)$ was spotted at four concentrations $(10,25,50$, and $100 \mu \mathrm{g} \mathrm{mL}^{-1}$ ) in replicates of two. Upon optimization, 50 and $100 \mu \mathrm{g} \mathrm{mL}^{-1} \mathrm{TTX}$ conjugate concentrations were selected and spotted in replicates of four per cartridge for the following experiments. In addition, fluorescently labeled BSA conjugate was spotted at $4 \mu \mathrm{g} \mathrm{mL} \mathrm{L}^{-1}$ at each of the four corners of the array to enable the proper alignment within the SnapESi reader. Printing buffer drops were spotted as negative controls between BSA and TTX conjugate spots. All printing procedures were performed at room temperature and $65 \%$ humidity. Printed waveguide arrays were then left at $25^{\circ} \mathrm{C}$ and $35 \%$ humidity overnight. 
After this, the waveguide arrays were blocked with casein solution for 5 min, rinsed with deionized water and dried by $1,000 \mathrm{rpm}$ centrifugation (SORVALL Legend RT, DJB Labcare Ltd, UK) for $5 \mathrm{~min}$. To fit the waveguides on the MBio reader, waveguides were inserted into cartridge housing that provided a flow channel of 5-mm-wide, 50-mm-long and $0.145-\mathrm{mm}$ high. The building process was completed with the addition of an adsorbent pad and a top cover. Cartridge components and the SnapEsi LS system were supplied by MBio Diagnostics Inc. (Boulder, Colorado, US).

\subsection{Immunosensor protocol}

MBio cartridges were placed on a cartridge rack at a special angle to enhance fluidic flow. The protocol was similar to that described by McGrath and co-workers [45]. The Ttotal assay time was 10 min. First, $150 \mu \mathrm{L}$ of 1/500 mAb dilution:standard TTX or sample (1:1, v:v) were applied to the cartridge for $5 \mathrm{~min}$, followed by $150 \mu \mathrm{L}$ of $10 \mu \mathrm{g} \mathrm{mL}^{-1}$ Alexa Fluor $647 \mathrm{GaM}$ IgG solution for 5 min. Each cartridge was then read on the MBio assay reader. Initially, different time exposures were collected, ranging from 25 to $100 \mathrm{~ms}$ of exposure. After this evaluation, readings were recorded at the fixed time point $75 \mathrm{~ms}$ after sample addition and were exported into Microsoft Excel for data analysis.

\subsubsection{Preparation of buffer calibration curves and data analysis}

A stock solution of $1,000 \mu \mathrm{g} \mathrm{L}^{-1}$ was used to prepare TTX calibrants at concentrations of 0 , $0.5,1,2.5,5,10$ and $100 \mu \mathrm{g} \mathrm{L}^{-1}$ in MBio assay buffer. These working standards were equivalent to $0,0.08,0.16,0.4,0.8,1.6$ and $16 \mu \mathrm{g} \mathrm{TTX} \mathrm{g}{ }^{-1}$ puffer fish. A calibration curve was prepared for each conjugate concentration. Two cartridges $(n=2)$ were used for each TTX working standard. Each cartridge consisted of a total of 16 spots, 8 spots per conjugate concentration. 
Curves were normalized with respect to the controls without TTX $\left(0 \mu \mathrm{g} \mathrm{L}^{-1}\right)$ and fitted to a sigmoidal logistic four-parameter equation using SigmaPlot software 12.0 (Systat Software Inc., California, US). The concentrations of TTX in the samples were then interpolated from these curves. In order to compare the response obtained with both TTX conjugate concentrations, data was first tested for normality using the Shapiro-Wilk test. For data following a normal distribution, t-test was performed; otherwise, Mann-Whitney Rank Sum Test was done. The level of significance was set at $p<0.05$. Finally, correlation between both TTX conjugate concentrations was evaluated using the linear regression model. All statistics were carried out using Sigmastat 3.1 software (Systat Software Inc., California, US).

The sensitivity $\left(\mathrm{IC}_{50}\right)$ and dynamic range $\left(\mathrm{IC}_{20}-\mathrm{IC}_{80}\right)$ of the assay were determined from the calibration curves obtained. The LOD for the present work was defined as the $20 \%$ inhibitory concentration $\left(\mathrm{IC}_{20}\right)$, which corresponds to the concentration of toxin required to decrease the response by $20 \%$ compared to the response when no toxin is present in the system (100\% mAb binding).

\subsection{Evaluation of puffer fish matrix effects and toxin recovery}

For puffer fish matrix calibration curves, aliquots of $1 \mathrm{~g}$ of negative puffer fish muscle tissue homogenate were fortified with $20 \mu \mathrm{L}$ of several concentrations of TTX and then extracted. Additionally, negative puffer tissue was extracted and then fortified with TTX (50 $\mu \mathrm{L}$ of TTX solution to $950 \mu \mathrm{L}$ MBio assay buffer). With this procedure, puffer fish tissue and puffer fish extracts were fortified with TTX at $0,0.08,0.16,0.4,0.8,1.6$ and $16 \mu \mathrm{gTTX} \mathrm{g}{ }^{-1}$ puffer fish. The spiking protocol was designed for the regulatory limit for PSP of $0.8 \mu \mathrm{g}$ STX equiv. $\mathrm{g}^{-1}$ tissue to fall within the middle of the calibration curves pre and post-extraction, thus ensuring the capability of the present method to screen TTX effectively at this concentration. Both, TTX fortified-puffer fish tissue and extracts were 40-fold diluted in MBio assay buffer and then run on the immunosensor for subsequent analysis. Curves were analyzed and 
compared to that prepared in buffer in order to evaluate the puffer fish matrix effects and to measure the TTX recovery under experimental conditions. Sensitivity $\left(\mathrm{IC}_{50}\right)$ and dynamic range $\left(\mathrm{IC}_{20}-\mathrm{IC}_{80}\right)$ of the assay for the three curves were obtained by fitting the data to sigmoidal, logistic, four-parameter equations. The LOD, defined previously as the $20 \%$ inhibitory concentration $\left(\mathrm{IC}_{20}\right)$, was calculated from an average of two replicates of calibration curves. In order to calculate the toxin recovery, mAb binding percentages obtained at TTX fortification levels of 0.4 and $0.8 \mu \mathrm{g} \mathrm{g}^{-1}$ of puffer fish tissue were compared to the fortification levels.

\subsection{Repeatability studies}

The performance of the method was assessed using the PSP toxin maximum permitted level of $0.8 \mu \mathrm{g}$ STX equivalents (equiv.) $\mathrm{g}^{-1}$ shellfish, since no regulatory limit is currently set within EC legislation for TTX. This repeatability study was carried out at two levels of TTX fortification $\left(0.8\right.$ and $\left.0.4 \mu \mathrm{g} \mathrm{g}^{-1}\right)$ and by the analysis of 5 replicates $(n=5)$ of a single puffer fish sample. Each replicate was extracted and 40-fold diluted in MBio assay buffer for analysis. Then, toxin recoveries as well as relative standard deviation (RSD) at each fortification level were calculated using the response value obtained from each individual analysis. Additionally, the same extracts were reanalyzed the following day, and toxin recoveries and $\mathrm{RSD}$ values at each fortification level were calculated.

\subsection{Puffer fish sample analysis and comparison with analytical, biological and biochemical assays, and biosensors}

Different tissues and species of puffer fish $(n=12)$ were analyzed (16 replicates each) by the present method using the extraction method previously detailed. Once extracted, samples were 40-fold diluted in MBio assay buffer. Specifically, 2 muscle samples, 2 liver samples, 
2 skin samples and $1 \mathrm{Gl}$ tract from 3 individuals of $L$. sceleratus, and 5 muscle samples from 5 individuals of $L$. lunaris were analyzed, and TTX contents expressed in $\mu \mathrm{g} \mathrm{g}^{-1}$ were calculated and compared with other analytical techniques. Puffer fish tissues were split into two groups, named as set 1 and set 2, according to the other techniques used to analyze the samples. Therefore, set 1 includes samples 1-5 (L. lunaris samples), which were analyzed by LC-MS/MS, RBA, ELISA and SPR biosensor. Analysis methods and data of this first set of samples was previously described in the work performed by Cohen and coworkers [19] and Yakes and colleagues [46]. Set 2 comprises three different fish ( $L$. sceleratus samples) with different tissues: 6 (muscle), 7.A (Gl tract), 7.B (liver), 7.C (skin), and 8.A (liver), 8.B (skin) and8.C (muscle), previously analyzed by LC-MS/MS and MBA. Analysis methods and data of the second set were described in the work performed by Katikou and co-workers [47] and Rodríguez and colleagues [48], respectively. Statistics to compare data obtained with different methods was performed following the same procedure used to compare data from calibration curves of both TTX conjugate concentrations. TTX concentrations in these samples was achieved by taking into account the mAb binding inhibitory concentration of the sample (within the dynamic range $I C_{20}-I C_{80}$ ) from the associated calibration curve. Those samples that showed responses above $80 \%$ were further diluted to bring their fluorescence signals within the dynamic range of the calibration curve. 


\section{Results and discussion}

Given the increasing concern about the prevalence of TTXs in fish and shellfish products in European waters and the high potency of these toxins, increased monitoring through the development of rapid, sensitive and robust methods is needed to ensure human health protection. With the aim of replacing animal use methods such as the MBA for TTX detection, in the present work the development of a sensitive planar waveguide-based biosensor able to detect TTX in multiple puffer fish tissues is described.

\subsection{Immunosensor protocol optimization}

Following the improved MBio procedure described by McGrath and co-workers [45], TTXjeff-KLH conjugate concentration and mAb dilution were firstly optimized. Of the four spotted TTX conjugate concentrations $\left(10,25,50\right.$ and $\left.100 \mu \mathrm{g} \mathrm{mL}^{-1}\right)$, those that gave a fluorescence value below 150 or above 500 when no TTX was present, were discarded. Following this criteria, 10 and $25 \mu \mathrm{g} \mathrm{mL}^{-1}$ TTX conjugate concentrations were no longer used. As such, given that the spotting of TTX conjugate at 50 and $100 \mu \mathrm{g} \mathrm{mL}^{-1}$ provided similar responses, both concentrations were selected for comparison in subsequent experiments. The capacity of the immobilized TTX conjugates to inhibit the mAb binding response was then assessed using $1 / 250$ and $1 / 500 \mathrm{mAb}$ dilutions at $100 \mu \mathrm{g} \mathrm{L}^{-1}$ of TTX standard. At both antibody dilutions, this TTX concentration was able to completely inhibit the mAb binding. However, as a lower antibody concentration generally results in a higher sensitivity, the $1 / 500 \mathrm{mAb}$ dilution was selected for the assay. With the experimental parameters set at TTX conjugate spotting concentrations of 50 and $100 \mu \mathrm{gL}^{-1}, \mathrm{mAb}$ at 1/500 dilution and fluorescentlylabeled GaM IgG antibody at $10 \mu \mathrm{g} \mathrm{m}^{-1}$ (concentration set through checkerboard titration in the work performed by Meneely and colleagues [49]), the whole calibration curves were performed in buffer. 


\subsection{Assay sensitivity determined from buffer calibration curves}

Calibration curves obtained for both TTX conjugate spotting concentrations in MBio assay buffer are shown in Figure $2 \mathrm{a}$ and $\mathrm{b}$, and, the midpoint $\left(\mathrm{IC}_{50}\right)$, limit of detection (LOD) and dynamic range determined are shown in Table 1 . The $I_{50}$ and LOD values were fairly similar at both spotting concentrations $(P=0.797 ; T=0.275)$ with a correlation of $y=1.45 x$ 1.72. A narrower dynamic range was obtained with $100 \mu \mathrm{g} \mathrm{mL}^{-1}$ of TTX conjugate, likely due to the binding kinetics effects of reduced competition in binding with additional coating antigen on the arrayed surface. $\mathrm{IC}_{50}$ and LOD values provided by this new immunosensor (6.0 and $2.5 \mathrm{\mu g} \mathrm{L}^{-1}$, respectively), compared well with a previous indirect SPR immunosensor that used the same antibody (6.6 and $2.4 \mathrm{\mu g} \mathrm{L}^{-1}$, respectively) [32], as well as with an SPR biosensor that employed a commercial antibody (approximately 6 and $0.3 \mu \mathrm{g} \mathrm{L}^{-1}$, respectively) [33]. Further, the $\mathrm{IC}_{50}$ values of the sensor developed herein were better than those recently reported for other indirect SPR immunosensors for TTX on a commercial instrument ( $\left(\mathrm{IC}_{50}\right.$ of 28.9 and $\mathrm{IC}_{20}$ of $\left.7.8 \mu \mathrm{g} \mathrm{L}^{-1}\right)$ [46] and from the average of three laboratories (IC 50 of 74 and $\mathrm{IC}_{20}$ of $\left.14 \mu \mathrm{g} \mathrm{L}^{-1}\right)$ [35]). As such, the sensitivity achieved in buffer was determined to be suitable for further assay development and the evaluation of matrix effects.

\subsection{Evaluation of puffer fish matrix effects and toxin recovery}

In order to demonstrate the applicability of the method to the analysis of real samples, matrix effects of puffer fish and of the extraction protocol procedure were investigated through spiking TTX into puffer fish extracts and into puffer fish fish tissue homogenates, respectively. Calibration curves obtained for both TTX conjugate spotting concentrations in buffer and in puffer fish matrix fortified pre and post-extraction are shown in figure 2. As the curves essentially overlap in the dynamic range of the assay, it can be concluded that there were little matrix effects from the puffer fish tissue and extraction procedure when these are 
diluted and run on the immunosensor. Furthermore, TTX concentrations and toxin recoveries obtained pre and post-extraction are shown in Table 2.

TTX concentrations determined in fortified-puffer fish extracts were similar to those obtained in buffer $(P=1.000 ; T=5.000)$. Statistically, no significant differences were found between the 50 or $100 \mu \mathrm{gL}^{-1}$ TTX conjugate surfaces for both fortification levels $(P=0.667 ; T=6.000$; $y=0.98 x+0.01)$. These similar results demonstrate that there are negligible puffer fish matrix effects on the system.

With regard to TTX concentrations determined when spiking TTX in puffer fish tissues, appropriate recovery values were obtained, and these concentrations were similar to the TTX fortification levels $(P=1.000 ; T=5.000)$. These accurate recovery values demonstrated the good efficiency of the extraction protocol and that there were limited toxin losses during the extraction process. Again, no significant differences were found between using 50 or $100 \mu \mathrm{g} \mathrm{mL} \mathrm{L}^{-1}$ of TTX conjugate $(\mathrm{P}=0.667 ; \mathrm{T}=5.500 ; y=1.03 x-0.03)$. TTX concentrations obtained in fortified-puffer fish tissues were also similar to that in fortified-puffer fish extracts $(P=1.000 ; T=5.000)$, reaffirming the negligible matrix effects on the biosensor and that accurate results from natural samples could be obtained.

\subsection{Repeatability studies}

The five homogenate-tissue samples fortified at 0.8 as well as five at $0.4 \mu \mathrm{g} \mathrm{g}^{-1}$ extracted and analyzed over two days, showed acceptable toxin recovery values. Specifically, results expressed in percentage values with respect to the TTX-fortified concentration ( 0.8 or 0.4 $\mu \mathrm{g} \mathrm{g}^{-1}$ ) and determined from the calibration curve in buffer were 89.1 and $78.5 \%$ for TTXconjugate spotted at $50 \mu \mathrm{g} \mathrm{mL}^{-1}$ and 106.3 and $106.8 \%$ for $100 \mu \mathrm{g} \mathrm{mL}^{-1}$ of conjugate, respectively, on day 1 . Similarly, the same extracts reanalyzed on day 2 provided toxin recoveries of 81.5 and $97.6 \%$ for $50 \mu \mathrm{g} \mathrm{mL}^{-1}$ of conjugate and 96.6 and $107.3 \%$ for $100 \mu \mathrm{g}$ 
$\mathrm{mL}^{-1}$ of conjugate. To assess the repeatability of the present sensor, precision was expressed as the RSD of the results , according to the 2012 AOAC International Guidelines [50]. Hence, on day $1, \mathrm{RSD}$ values with respect to $50 \mu \mathrm{g} \mathrm{mL}^{-1}$ of TTX conjugate were $14.6 \%$ for $0.8 \mu \mathrm{g} \mathrm{g}^{-1}$ and $10.8 \%$ for $0.4 \mu \mathrm{g} \mathrm{g}^{-1}$, while values were $9.9 \%$ for the $0.8 \mu \mathrm{g} \mathrm{g}^{-1}$ and $2.1 \%$ for the $0.4 \mu \mathrm{g} \mathrm{g}^{-1}$ for TTX conjugate $100 \mu \mathrm{g} \mathrm{mL}^{-1}$. On day 2, RSD values were 12.5 and $8.3 \%$ for $50 \mu \mathrm{gLL}^{-1}$ of TTX conjugate and, 10.4 and 13.1 for $100 \mu \mathrm{gL}^{-1}$ of TTX conjugate at 0.8 and $0.4 \mu \mathrm{g} \mathrm{g}^{-1}$, respectively. Considering the expected precision as a function of analyte concentration, RSD values for 0.8 and $0.4 \mu \mathrm{g}$ toxin $\mathrm{g}^{-1}$ puffer fish tissue should be lower than $15 \%$, and all the obtained RSD values for this assay were below this value. It should be noted that this was a comparison of extracts between days and not re-extraction of the fish due to limitations in toxin availability. Nevertheless, this results illustrate the degree of repeatability in analysis. Additionally, the toxin recovery values obtained in same extracts on day 2, demonstrate that samples containing TTX were stable at least for 1 day. All these results demonstrated that the new planar waveguide biosensor allowed for suitable precision under repeatability conditions within independent tests and that already extracted samples could be reanalyzed on the following day with the same precision. Additionally, differences between values obtained with both TTX conjugate concentrations were statistically not significant. The good agreement of the results provided by this repeatability study at 0.8 and $0.4 \mu \mathrm{g} \mathrm{TTX} \mathrm{g^{-1 }}$ fish tissue confirmed the feasibility and reliability of the planar waveguide biosensor for being applied to the analysis of real samples.

\subsection{Puffer fish samples analysis and comparison with other methods}

Table 3 shows the TTX concentrations determined per $g$ of puffer fish tissue by the nanoarray-based biosensor as well as by other analytical and biochemical methods. In 
general, TTX contents determined in the samples provided by the present biosensor correlated well with the data reported by the other methods.

Among the 12 puffer fish samples analyzed, 4 samples ( 1 and 5 muscle tissues from L. Iunaris, and 8.B (skin) and 8.C (muscle) from L. sceleratus) were found to contain TTX contents below the regulated Japanese level of $2 \mu \mathrm{g} \mathrm{TTX} \mathrm{g}{ }^{-1}$ fish tissue by all the techniques. With respect to the other samples, within the $L$. lunaris samples (Set 1 , Table $3 a$ ), the trend from the most to the lowest toxic muscle tissue was: $4>3>2>1>5$ for all the techniques employed. The high concentrations of TTX found in muscle tissue extracts 3 and 4 from $L$. Iunaris individuals were in accordance with the high contents of TTX found in the meat of this species of puffer fish, which is a causative source of food poisonings worldwide [51]. On the contrary, the distribution of TTX found among the L. sceleratus tissues from the most to the lowest toxicity was: Gl-tract (7.A) > liver (7.B, 8.A) > skin (7.C, 8.B) $\geq$ muscle $(6,8 . C)$. Again, the toxin distribution found within tissues agrees well with that reported for $L$. sceleratus species $[3,52]$, as the gastrointestinal tract is expected to be the most toxic, followed by the liver and finally by the skin and muscle.

In the analysis of the first set of samples (1-5), excellent correlation was obtained between the TTX contents determined by the planar-waveguide biosensor at both conjugate concentrations $\left(y=1.06 x-0.11 ; R^{2}=0.996 ; \mathrm{P}=1.000 ; \mathrm{T}=27.500\right)$. Because of this similarity (differences statistically not significant) and to simplify the results, the comparison with other methods was only performed with reference to the $100 \mu \mathrm{g} \mathrm{mL}^{-1}$ conjugate surface. When comparing the quantifications provided by the planar waveguide biosensor with those LCMS/MS values reported previously in Cohen and co-workers [19] and Yakes and colleagues [46], higher TTX contents were reported by the biosensor with a correlation of $y=1.70 x-0.08$ $\left(R^{2}=0.987\right)$ obtained, although the differences were statistically not significant $(\mathrm{P}=0.517$; $\mathrm{T}=0.677)$. The higher TTX concentrations in the $L$. lunaris muscle samples determined by the biosensor could be attributed to the fact that the previous LC-MS/MS quantifications for 
these samples were determined solely for TTX while the mAb used herein may react with multiple TTX analogues potentially present in the puffer fish samples. Rodriguez and coworkers [48] found multiple TTX analogs in the closely related species $L$. sceleratus, several of which were in higher concentration than TTX itself. Most of these analogs are less potent than TTX, as evidenced by the poor correlation to MBA data in that study. It is not currently known if these same TTX analogs are also present in L. lunaris and what their contributions are to total toxicity. This possibility was supported by the correlation obtained by RBA and the planar-waveguide biosensor $\left(y=1.32 x-0.36 ; R^{2}=0.994 ; \mathrm{P}=0.757 ; \mathrm{T}=0.320\right)$. The high TTX concentration achieved by the biosensor in this case could also be due to the different affinity between the two biorecognition molecules (mAb for the waveguide and sodiumchannel receptor for the RBA) as well as the final reporting element (fluorescently labeled secondary antibody for the waveguide and $\mathrm{H}^{3}$-STX for the RBA).

The same trend was observed when comparing the waveguide assay data to that obtained by ELISA $\left(y=1.12 x+0.36 ; \quad R^{2}=0.933 ; \quad \mathrm{P}=0.489 ; \quad \mathrm{T}=0.725\right)$ and $\mathrm{SPR}$ immunosensor $\left(y=1.70 x+0.02 ; R^{2}=0.986 ; \mathrm{P}=0.510 ; \mathrm{T}=0.690\right)$. Although data obtained by the biosensor was similar to that obtained by ELISA and SPR immunosensor, small differences in determining TTX content can similarly be attributed to differences in biorecognition elements and transduction techniques. Specifically, in the SPR biosensor the TTX was chemically immobilized on dextran chips, and the signal was measured in real time. In ELISA and the waveguide sensor, TTX-conjugate was coated on wells and on nanoarrays, respectively, which likely resulted in the slightly different responses. Furthermore, although both ELISA and the biosensor are indirect strategies that use a secondary labeled antibody, the final output is given by the absorbance of an enzyme in ELISA and by fluorescence in the biosensor. Although TTX contents determined by the planar waveguide biosensor were slightly higher than those reported by the other techniques, they were still in good 
agreement. Within this set of samples, the trend from higher to lower TTX concentrations was the same by all techniques.

With regard to the second set of samples, excellent correlation was obtained between data provided by the present biosensor for both conjugate concentrations $(y=1.07 x-0.39$; $\left.R^{2}=0.998\right)$, with no significant statistical difference $(P=0.902 ; T=51.00)$. As for the first set of samples, data provided by the biosensor using $100 \mu \mathrm{g} \mathrm{mL}^{-1}$ of conjugate was used for further comparison. As observed in other works [27], TTX concentrations determined by the planar waveguide biosensor were generally slightly lower than those reported by MBA, but the data were still in good agreement $\left(y=0.74 x+0.42 ; R^{2}=0.987\right)$, with the differences statistically not significant $(P=1.000 ; T=27.000)$. The overestimation of the TTX contents provided by MBA is attributed to the different principle of the techniques; specifically, MBA reports global toxicity using animal models and could detect co-existing toxins other than TTXs. Moreover, since no cross-reactivity data of the TTX analogues is available for this biosensor and antibody and toxin equivalency factors (TEFs) are not well-established, the biosensor response was not necessarily expected to fully match the MBA data.

Different scenarios were assumed when comparing the TTX contents obtained with the current biosensor to those determined by LC-MS/MS analysis. If only individual TTX is evaluated, the data correlated quite well $\left(R^{2}=0.945\right)$ but much higher TTX contents were determined by the biosensor $(y=3.16 x+0.76)$. These differences in the concentrations, although statistically not significant $(P=0.310 ; T=1.109)$, seem to indicate that some of the TTX analogues detected in the LC-MS/MS were also recognized by the antibody. In the second scenario, TTX analogues were considered to have the same mAb affinity as TTX, thus with a cross-reactivity factor (CRF) of 1 . Unfortunately, worse correlation $\left(R^{2}=0.702\right)$ and higher overestimation $(y=8.83 x+28.91)$ were obtained compared to LC-MS/MS analysis using this scenario. This underestimation of LC-MS/MS analysis with respect to the planar waveguide biosensor suggests that not all the TTX analogues were recognized by the 
antibody in the MBio biosensor, or they are recognized with low affinity. Looking at the LCMS/MS individual concentrations, it seems evident that the analogues 5,6,11-trideoxy-TTX (1 and 2) cannot be recognized by the antibody at the same extent as TTX (i.e., much higher quantifications would have been obtained with the planar waveguide biosensor for 7.A (GI tract) and 7.B (liver) samples). Moreover, this analogue has been considered almost nontoxic by other authors [52].

As an intermediate approach, only 4-epiTTX, 4,9-anhydroTTX, 5-deoxyTTX and 11deoxyTTX were theorized to be recognized by the antibody with same affinity than TTX. In this case, excellent correlations $\left(R^{2}=0.954\right)$ and similar quantifications $(y=1.07 x+0.68)$ were obtained between MBio biosensor and LC-MS/MS analysis ( $P=0.690 ; T=30.000)$. Of course, this criterion was used only to demonstrate that results can change to a high extent depending on the analogues considered. Ideally, and according to what has been previously published [27], to better compare the concentrations obtained by the biosensor to that provided by LC-MS/MS, CRFs of the antibody towards co-existing TTX analogues should be established and applied to the individual measurements determined by LC-MS/MS. Unfortunately, TTX analogue standards were not available to investigate this issue in detail. As for the general results, the biosensor, MBA and LC-MS/MS were in agreement in determining the gastrointestinal tract as the most toxic tissue, followed by the liver tissue of L. sceleratus species. Due to the low TTX content, it was more difficult to observe a trend in muscle and skin tissues by the different methods used herein.

Notably, the present biosensor was proven to be useful as screening tool and was also capable of rapidly (in $10 \mathrm{~min}$ ) detecting trace TTX contents, thereby meeting the requirements in terms of sensitivity not only of the Japanese regulation but also of the similar mode-of-action PSP toxins legislation. 


\section{Conclusions}

The present work reported the development of a rapid and specific nanoarray planar waveguide biosensor for the determination of TTX concentration in puffer fish samples. The biosensor attained good sensitivity (LOD of $2.5 \mu \mathrm{g} \mathrm{L}^{-1}$ ), thus being capable of detecting TTXs as low as $0.4 \mu \mathrm{g} \mathrm{g}^{-1}$ puffer fish. This concentration is below the EU and US regulatory limit of $0.8 \mu \mathrm{g}$ STX equiv. $\mathrm{g}^{-1}$ shellfish meat for the similar PSP toxins and can be used as a guide. Additionally, the negligible effects of puffer fish matrix on the biosensor and the excellent toxin recoveries obtained reinforce the reliability and applicability of the innovative method. This is further evidenced by the general agreement found between the TTX concentrations determined by the biosensor and the other methods (LC-MS/MS, RBA, ELISA, MBA and SPR biosensor) in the analysis of naturally-contaminated puffer fish samples of different species.

This biosensor configuration presents multiple benefits, including simplicity and rapidity of the assay, design versatility, small reagent volumes, good reproducibility, and accurate and precise toxin quantifications. In addition to these advantages, this nanoarrayed configuration could be used together with other related toxins for simultaneous multi-toxin detection, which represents a breakthrough in the development of compact, multiplexed devices. Despite the planar waveguide technology not being new per se, this is the first immunosensor using this technique that has been specifically developed for TTX. Thus, this new approach can be considered as a proof of concept, being not only applicable to TTX but also to other emerging toxins of seafood safety and environmental surveillance fields.

On the whole, the biosensor described herein has been proven to be a promising highthroughput sample screening tool for implementation in research and monitoring programs, being able to analyze multiple samples with toxin contents below the permitted levels of concern. Furthermore, taking into consideration the presence of TTX recently reported in 
European shellfish mollusks of England, Greece and Netherlands, the biosensor developed herein could have suitable sensitivity, at lower proposed action levels, to be applicable to shellfish by only slightly modifying the sample preparation.

\section{Acknowledgements}

This research was funded through the Advanced ASSET project, partly funded through InvestNI and the European Sustainable Programme 2007-2013 under the European Regional Development Fund. The authors would like to acknowledge funding received from the CERCA Programme/Generalitat de Catalunya. The authors would like to thank Sara McNamee for technical support and training in the use of equipment, and Stacey DeGrasse and Kevin White for their previous work on the analytical detection of tetrodotoxin in samples. 


\section{References}

[1] EG Moczydlowski, The molecular mystique of tetrodotoxin, Toxicon, 63(2013) 165-83.

[2] V Pratheepa, V Vasconcelos, Microbial diversity associated with tetrodotoxin production in marine organisms, Environ. Toxicol. Pharmacol., 36(2013) 1046-54.

[3] T Noguchi, O Arakawa, Tetrodotoxin - Distribution and accumulation in aquatic organisms, and cases of human intoxication, Mar. Drugs, 6(2008) 220-42.

[4] P Rodriguez, A Alfonso, C Vale, C Alfonso, P Vale, A Tellez, et al., First toxicity report of tetrodotoxin and 5,6,11-trideoxyTTX in the trumpet shell Charonia lampas lampas in Europe, Anal. Chem., 80(2008) 5622-9.

[5] AD Turner, A Powell, A Schofield, DN Lees, C Baker-Austin, Detection of the pufferfish toxin tetrodotoxin in European bivalves, England, 2013 to 2014, Eurosurveill., 20(2015a) 2-8.

[6] A Vlamis, P Katikou, I Rodriguez, V Rey, A Alfonso, A Papazachariou, et al., First Detection of Tetrodotoxin in Greek Shellfish by UPLC-MS/MS Potentially Linked to the Presence of the Dinoflagellate Prorocentrum minimum, Toxins, 7(2015) 1779-807.

[7] Y Bentur, J Ashkar, Y Lurie, Y Levy, ZS Azzam, M Litmanovich, et al., Lessepsian migration and tetrodotoxin poisoning due to Lagocephalus sceleratus in the eastern Mediterranean, Toxicon, 52(2008) 964-8.

[8] PS McNabb, DI Taylor, SC Ogilvie, L Wilkinson, A Anderson, D Hamon, et al., First Detection of Tetrodotoxin in the Bivalve Paphies australis by Liquid Chromatography Coupled to Triple Quadrupole Mass Spectrometry With and Without Precolumn Reaction, J. AOAC Int., 97(2014) 325-33.

[9] T Noguchi, K Onuki, O Arakawa, Tetrodotoxin poisoning due to pufferfish and gastropods, and their intoxication mechanism, ISRN toxicol., 2011(2011) article ID 276939, 10 pages. doi:10.5402/2011/276939

[10] A Alcaraz, RE Whipple, HR Gregg, BD Andresen, PM Grant, Analysis of tetrodotoxin, Forensic Sci. Int. , 99(1999) 35-45.

[11] K Tsuda, R Tachikawa, C Tamura, S Ikuma, M Kawamura, K Sakai, et al., On structure of tetrodotoxin, Chem. Pharm. Bull., 12(1964) 1357-74.

[12] RB Woodward, JZ Gougouta, Structure of tetrodotoxin, J. Am. Chem. Soc., 86(1964) 50305030. doi: 10.1021/ja01076a076

[13] RJ French, D Yoshikami, MF Sheets, BM Olivera, The Tetrodotoxin Receptor of VoltageGated Sodium Channels-Perspectives from Interactions with mu-Conotoxins, Mar. Drugs, 8(2010) 2153-61.

[14] CH Lee, PC Ruben, Interaction between voltage-gated sodium channels and the neurotoxin, tetrodotoxin, Channels, 2(2008) 407-12.

[15] M Yotsu-Yamashita, A Sugimoto, A Takai, T Yasumoto, Effects of specific modifications of several hydroxyls of tetrodotoxin on its affinity to rat brain membrane, J. Pharmacol. Exp.

Ther., 289(1999) 1688-96.

[16] T Kawabata, The manual for the methods of food sanitation tests . Bureau of Environmental Health, Ministry of Health and Welfare, Japan Food Hygienic Association, Tokyo, Japan, 1978, pp. 232-40.

[17] US FDA, Exchange of letters between Japan and US Food and Drug Administration regarding puffer fish. In International cooperative agreements manual. p. 57-73. Available at: http://www.fda.gov/InternationalPrograms/Agreements/MemorandaofUnderstanding/ucm10 7601.htm. Accessed 9 October 2016, 1989.

[18] US FDA, Import Alert \#16-20: Detention without physical examination of puffer fish and foods that contain puffer fish. http://www.accessdata.fda.gov/cms_ia/importalert_37.html Accessed by October 2016, 2015.

[19] NJ Cohen, JR Deeds, ES Wong, RH Hanner, HF Yancy, KD White, et al., Public Health Response to Puffer Fish (Tetrodotoxin) Poisoning from Mislabeled Product, J. Food Prot., 72(2009) 810-7. 
[20] JB Cole, WG Heegaard, JR Deeds, SC McGrath, SM Handy, Tetrodotoxin Poisoning Outbreak from Imported Dried Puffer - Fish Minneapolis, Minnesota, 2014, Mmwr-Morbidity and Mortality Weekly Report, 63(2015) 1222-5.

[21] AD Turner, C Higgins, W Higman, J Hungerford, Potential Threats Posed by Tetrodotoxins in UK Waters: Examination of Detection Methodology Used in Their Control, Mar. Drugs, 13(2015b) 7357-76.

[22] JF Lawrence, B Niedzwiadek, C Menard, Quantitative determination of paralytic shellfish poisoning toxins in shellfish using prechromatographic oxidation and liquid chromatography with fluorescence detection: Collaborative study, J. AOAC Int., 88(2005) 1714-32.

[23] M Asakawa, Shida, Y., Miyazawa, K., Noguchi, T., Chromatography - The Most Versatile Method of Chemical Analysis. Instrumental Analysis of Tetrodotoxin., InTech Open Science, Rijeka, Croatia, 2012, p. 245.

[24] K Kawatsu, Y Hamano, T Yoda, Y Terano, T Shibata, Rapid and highly sensitive enzyme immunoassay for quantitative determination of tetrodotoxin, Jpn. J. Med. Sci. Biol. , 50(1997) 133-50.

[25] D Neagu, L Micheli, G Palleschi, Study of a toxin-alkaline phosphatase conjugate for the development of an immunosensor for tetrodotoxin determination, Anal. Bioanal. Chem., 385(2006) 1068-74.

[26] TJG Raybould, GS Bignami, LK Inouye, SB Simpson, JB Byrnes, PG Grothaus, et al., A monoclonal antibody-based immunoassay for detecting tetrodotoxin in biological samples, J. Clin. Lab. Anal., 6(1992) 65-72.

[27] L Reverté, P de la Iglesia, V del Río, K Campbell, CT Elliott, K Kawatsu, et al., Detection of Tetrodotoxins in Puffer Fish by a Self-Assembled Monolayer-Based Immunoassay and Comparison with Surface Plasmon Resonance, LC-MS/MS, and Mouse Bioassay (vol 87, pg 10839, 2015), Anal. Chem., 88(2015) 2511-.

[28] AN Stokes, BL Williams, SS French, An improved competitive inhibition enzymatic immunoassay method for tetrodotoxin quantification, Biol. Proced. Online 14(2012) 3.

[29] R Wang, A Huang, L Liu, S Xiang, X Li, S Ling, et al., Construction of a single chain variable fragment antibody (scFv) against tetrodotoxin (TTX) and its interaction with TTX, Toxicon, 83(2014) 22-34.

[30] Y Zhou, YS Li, FG Pan, ZS Liu, Z Wang, Identification of tetrodotoxin antigens and a monoclonal antibody, Food Chem., 112(2009) 582-6.

[31] MP Kreuzer, M Pravda, CK O'Sullivan, GG Guilbault, Novel electrochemical immunosensors for seafood toxin analysis, Toxicon, 40(2002) 1267-74.

[32] K Campbell, P Barnes, SA Haughey, C Higgins, K Kawatsu, V Vasconcelos, et al., Development and single laboratory validation of an optical biosensor assay for tetrodotoxin detection as a tool to combat emerging risks in European seafood, Anal. Bioanal. Chem., 405(2013) 7753-63.

[33] AD Taylor, J Ladd, S Etheridge, J Deeds, S Hall, SY Jiang, Quantitative detection of tetrodotoxin (TTX) by a surface plasmon resonance (SPR) sensor, Sens. Actuat. B-Chem., 130(2008) 120-8.

[34] AD Taylor, H Vaisocherova, J Deeds, S DeGrasse, S Jiang, Tetrodotoxin Detection by a Surface Plasmon Resonance Sensor in Pufferfish Matrices and Urine, Journal of Sensors, (2011).

[35] H Vaisocherova, AD Taylor, S Jiang, K Hegnerova, M Vala, J Homola, et al., Surface Plasmon Resonance Biosensor for Determination of Tetrodotoxin: Prevalidation Study, J. AOAC Int., 94(2011) 596-604.

[36] BJ Yakes, J Deeds, K White, SL DeGrasse, Evaluation of Surface Plasmon Resonance Biosensors for Detection of Tetrodotoxin in Food Matrices and Comparison to Analytical Methods, J. Agric. Food Chem., 59(2011) 839-46.

[37] BJ Yakes, KM Kanyuck, SL DeGrasse, First Report of a Direct Surface Flasmon Resonance Immunosensor for a Small Molecule Seafood Toxin, Anal. Chem., 86(2014) 9251-5. 
[38] SE McNamee, CT Elliott, B Greer, M Lochhead, K Campbell, Development of a Planar Waveguide Microarray for the Monitoring and Early Detection of Five Harmful Algal Toxins in Water and Cultures, Environ. Sci. Technol., 48(2014) 13340-9.

[39] HA Bates, R Kostriken, H Rapoport, Chemical assay for saxitoxin - improvements and modifications, J. Agric. Food Chem., 26(1978) 252-4.

[40] K Campbell, SA Haughey, H van den Top, H van Egmond, N Vilarino, LM Botana, et al., Single Laboratory Validation of a Surface Plasmon Resonance Biosensor Screening method for Paralytic Shellfish Poisoning Toxins, Anal. Chem., 82(2010) 2977-88.

[41] K Campbell, LD Stewart, GJ Doucette, TL Fodey, SA Haughey, N Vilarino, et al., Assessment of specific binding proteins suitable for the detection of paralytic shellfish poisons using optical biosensor technology, Anal. Chem., 79(2007) 5906-14.

[42] RI Huot, DL Armstrong, TC Chanh, Protection against nerve toxicity by monoclonalantibodies to the sodium-channel blocker, J. Clin. Invest., 83(1989) 1821-6.

[43] HM Johnson, JE Campbell, R Angelotti, KH Lewis, PA Frey, Haptenic properties of paralytic shellifsh poison conjugated to proteins by formaldehyde treatment, Proc. Soc. Exp. Biol. Med. , 117(1964) 425-\&.

[44] J Tao, WJ Wei, L Nan, LH Lei, HC Hui, GX Fen, et al., Development of competitive indirect ELISA for the detection of tetrodotoxin and a survey of the distribution of tetrodotoxin in the tissues of wild puffer fish in the waters of south-east China, Food Addit. Contam. Part A 27(2010) 1589-97.

[45] TF McGrath, L McClintock, JS Dunn, GM Husar, MJ Lochhead, RW Sarver, et al., Development of a rapid multiplexed assay for the direct screening of antimicrobial residues in raw milk, Anal. Bioanal. Chem., 407(2015) 4459-72.

[46] BJ Yakes, J Deeds, K White, SL DeGrasse, Evaluation of Surface Plasmon Resonance Biosensors for Detection of Tetrodotoxin in Food Matrices and Comparison to Analytical Methods, J. Agric. Food Chem., 59(2011) 839-46.

[47] P Katikou, D Georgantelis, N Sinouris, A Petsi, T Fotaras, First report on toxicity assessment of the Lessepsian migrant pufferfish Lagocephalus sceleratus (Gmelin, 1789) from European waters (Aegean Sea, Greece), Toxicon, 54(2009) 50-5.

[48] P Rodriguez, A Alfonso, P Otero, P Katikou, D Georgantelis, LM Botana, Liquid chromatography-mass spectrometry method to detect Tetrodotoxin and Its analogues in the puffer fish Lagocephalus sceleratus (Gmelin, 1789) from European waters, Food Chem., 132(2012) 1103-11.

[49] JP Meneely, K Campbell, C Greef, MJ Lochhead, CT Elliott, Development and validation of an ultrasensitive fluorescence planar waveguide biosensor for the detection of paralytic shellfish toxins in marine algae, Biosens. Bioelectron., 41(2013) 691-7.

[50] AOAC, Guidelines for single laboratory validation of chemical methods for dietary supplements and botanicals. http://www.aoac.org/Official_Methods/slv_guidelines.pdf. Accessed by October 2016., 2012.

[51] CC Yang, SC Liao, JF Deng, Tetrodotoxin poisoning in Taiwan: An analysis of poison center data, Vet. Hum. Toxicol., 38(1996) 282-6.

[52] J Jang, M Yotsu-Yamashita, Distribution of tetrodotoxin, saxitoxin, and their analogs among tissues of the puffer fish Fugu pardalis, Toxicon, 48(2006) 980-7. 
Figure 1. Schematic representation of the planar waveguide immunosensor for TTX.

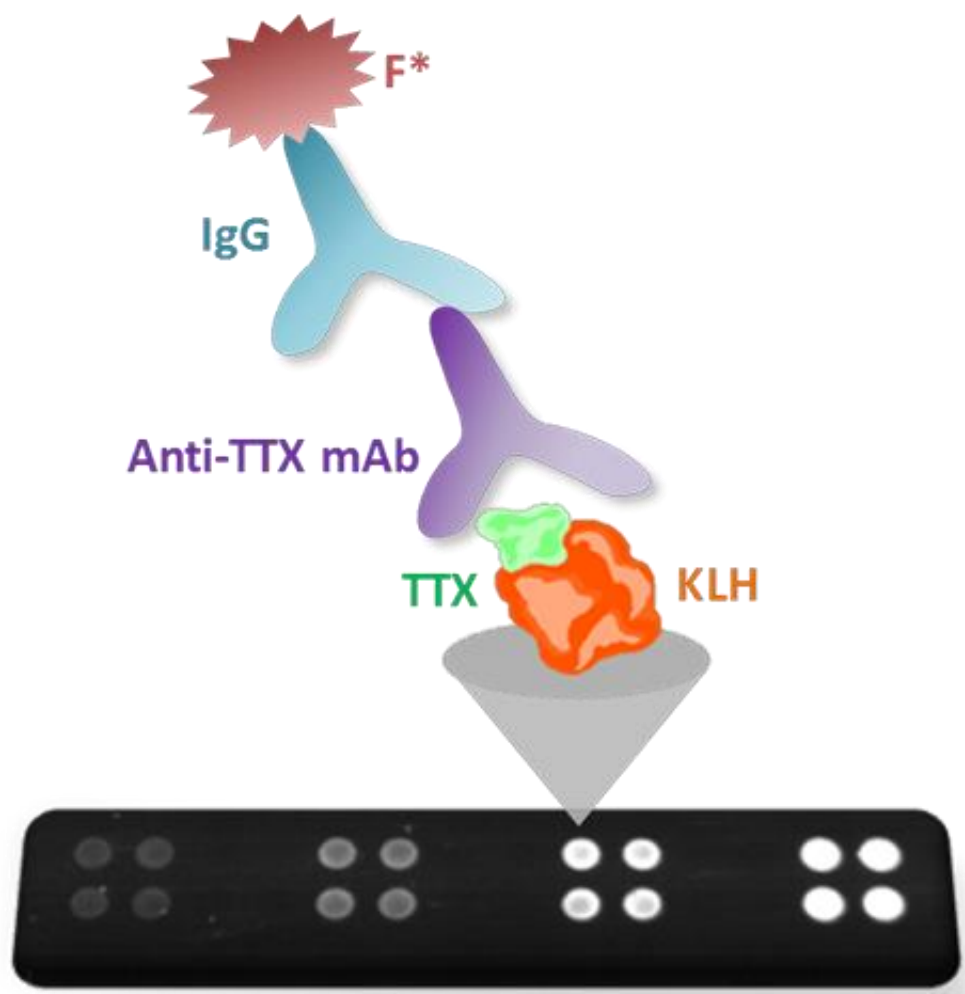

Planar waveguide nanoarray 
Figure 2. Calibration curves in buffer and fortified-puffer fish tissues and extracts obtained for a) $50 \mu \mathrm{g} \mathrm{mL}^{-1}$ and b) $100 \mu \mathrm{g} \mathrm{mL}^{-1} \mathrm{TTX}$-conjugate. Curves normalized to mAb signal when no TTX is present. Standard deviations for 16 replicates are represented by the error bars.
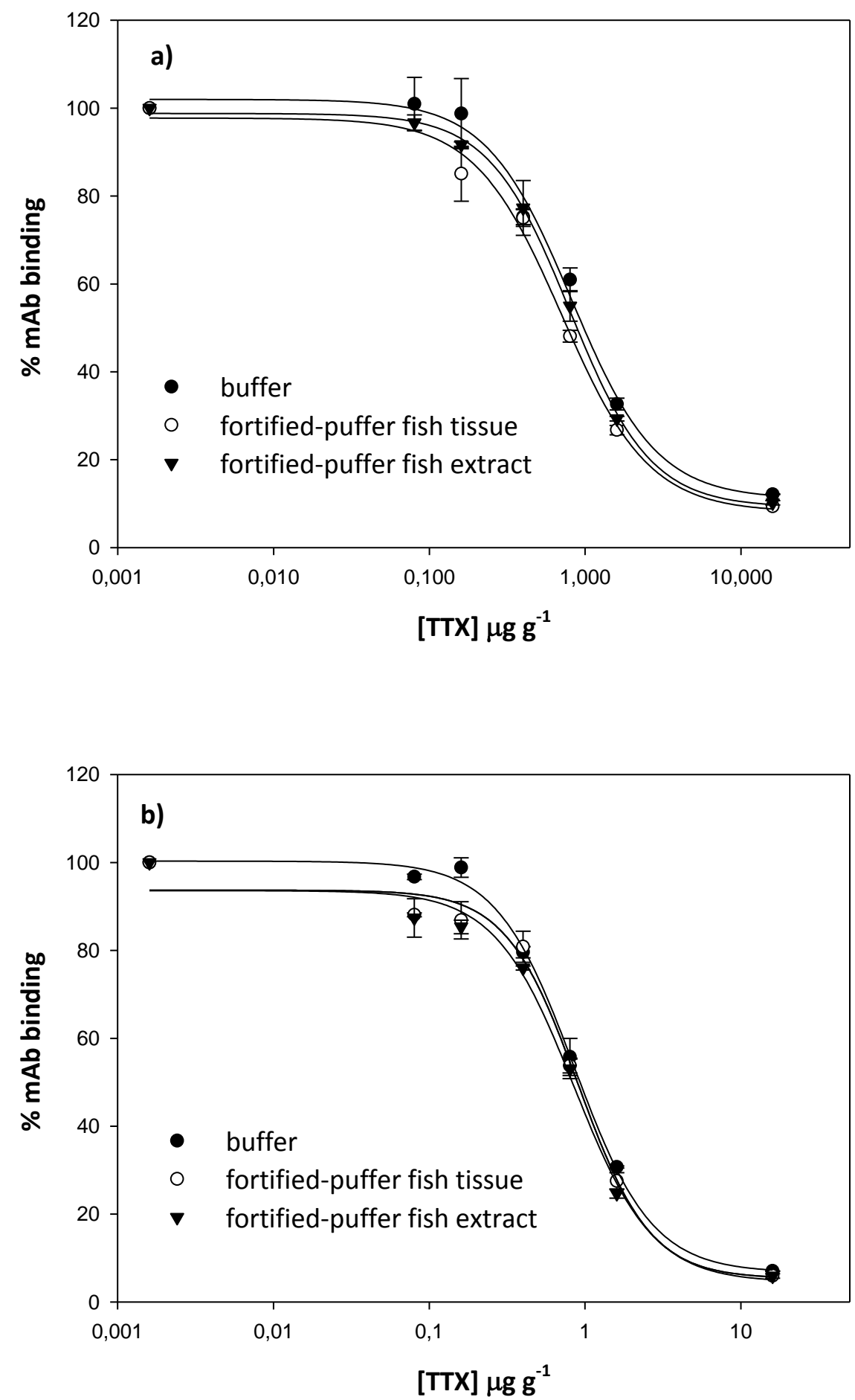
Table 1. Midpoint of the curve $\left(I_{50}\right)$, $L O D\left(I C_{20}\right)$ and dynamic range $\left(I C_{20}-I C_{80}\right)$ values \pm SD provided by the planar waveguide biosensor in buffer for both TTX conjugate concentrations and for 16 replicates.

\begin{tabular}{|c|c|c|c|}
\hline [TTX conjugate] & Midpoint $\left(\mathrm{IC}_{50}\right) \mu \mathrm{g} \mathrm{L}^{-1}$ & $\operatorname{LOD}\left(\mathrm{IC}_{20}\right) \mu \mathrm{g} \mathrm{L^{-1 }}$ & Dynamic range $\left(\mathrm{IC}_{20}-\mathrm{I} \mathrm{C}_{80}\right) \mu \mathrm{g} \mathrm{\textrm {L } ^ { - 1 }}$ \\
\hline $50 \mu \mathrm{g} \mathrm{mL}^{-1}$ & $6.1 \pm 0.5$ & $2.5 \pm 0.1$ & $2.5( \pm 0.1)-20.5( \pm 2.2)$ \\
\hline $100 \mu \mathrm{g} \mathrm{mL}^{-1}$ & $5.8 \pm 0.3$ & $2.6 \pm 0.1$ & $2.6( \pm 0.1)-15.2( \pm 1.7)$ \\
\hline
\end{tabular}

Table 2. TTX concentration \pm standard deviation for 16 replicates in fortifiedpuffer fish tissue and extracts determined by the planar waveguide biosensor. Toxin recovery is expressed in percentages (\%) and calculated with reference to the TTX fortification levels of 0.4 and $0.8 \mu \mathrm{g} \mathrm{TTX} \mathrm{g}^{-1}$ puffer fish.

\begin{tabular}{cccc}
\hline [TTX conjugate] & Matrix & \multicolumn{2}{c}{ TTX fortification level } \\
\cline { 3 - 4 } & fortified-puffer fish tissue & $0.82 \pm 0.03(102.5 \%)$ & $0.35 \pm 0.02(87.5 \%)$ \\
\hline $50 \mu \mathbf{g ~ m L ~}^{-1}$ & $0.78 \pm 0.06(97.5 \%)$ & $0.40 \pm 0.09(100.0 \%)$ \\
\hline $100 \mu \mathrm{g} \mathrm{mL}^{-1}$ & fortified-puffer fish extract & $0.81 \pm 0.03(101.3 \%)$ & $0.35 \pm 0.05(87.5 \%)$ \\
& fortified-puffer fish tissue & $0.77 \pm 0.06(96.3 \%)$ & $0.38 \pm 0.01(95.0 \%)$ \\
\hline
\end{tabular}




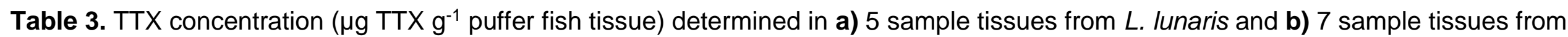
L. sceleratus by the MBio biosensor and comparison with other methods [46-48].

a)

\begin{tabular}{|c|c|c|c|c|c|c|}
\hline \multicolumn{7}{|c|}{$\mu \mathrm{g} T \mathrm{TX} \mathrm{g}^{-1}$ puffer fish tissue } \\
\hline \multirow[t]{2}{*}{ Sample code } & \multicolumn{2}{|c|}{ MBio biosensor } & \multirow{2}{*}{$\begin{array}{l}\text { LC-MS/MS } \\
\text { (TTX) [46] }\end{array}$} & \multirow{2}{*}{$\begin{array}{l}\text { RBA } \\
{[46]}\end{array}$} & \multirow{2}{*}{$\begin{array}{c}\text { ELISA } \\
{[46]}\end{array}$} & \multirow{2}{*}{$\begin{array}{l}\text { SPR } \\
{[46]}\end{array}$} \\
\hline & TTX conjugate $50 \mu \mathrm{g} \mathrm{mL}^{-1}$ & TTX conjugate $100 \mu \mathrm{g} \mathrm{mL}^{-1}$ & & & & \\
\hline 1 & $0.27 \pm 0.07$ & $0.31 \pm 0.04$ & 0.10 & 0.18 & 0.04 & 0.07 \\
\hline 2 & $3.38 \pm 0.08$ & $3.23 \pm 0.15$ & 2.14 & 3.52 & 2.68 & 2.47 \\
\hline 3 & $13.26 \pm 0.64$ & $13.49 \pm 0.64$ & 8.76 & 10.50 & 14.12 & 7.09 \\
\hline 4 & $19.02 \pm 5.19$ & $17.50 \pm 5.03$ & 9.61 & 13.24 & 12.48 & 10.74 \\
\hline 5 & $0.24 \pm 0.03$ & $0.24 \pm 0.07$ & 0.10 & 0.16 & 0.02 & 0.07 \\
\hline
\end{tabular}

b)

\begin{tabular}{|c|c|c|c|c|c|c|c|c|c|c|c|c|}
\hline \multicolumn{13}{|c|}{$\mu \mathrm{g} \mathrm{TTX} \mathrm{g}^{-1}$ puffer fish tissue } \\
\hline \multirow[b]{2}{*}{ Sample code } & \multicolumn{2}{|c|}{ MBio biosensor } & \multirow[b]{2}{*}{ MBA [47] } & \multicolumn{9}{|c|}{ LC-MS/MS [48] } \\
\hline & $\begin{array}{l}\text { TTX conjugate } \\
50 \mu \mathrm{g} \mathrm{m}^{-1}\end{array}$ & $\begin{array}{l}\text { TTX conjugate } \\
100 \mu \mathrm{g} \mathrm{mL}^{-1}\end{array}$ & & TTX & 4-epiTTX & $\begin{array}{c}4,9- \\
\text { anhydroTTX }\end{array}$ & $\begin{array}{c}5- \\
\text { deoxyTTX }\end{array}$ & $\begin{array}{c}11- \\
\text { deoxyTtX }\end{array}$ & $\begin{array}{c}11- \\
\text { norTTX- } \\
6(R)-o l\end{array}$ & $\begin{array}{c}11- \\
\text { norTTX- } \\
6(S)-o l\end{array}$ & $\begin{array}{c}5,6,11- \\
\text { trideoxyTTX (1) }\end{array}$ & $\begin{array}{c}5.6 .11- \\
\text { trideoxyTTX (2) }\end{array}$ \\
\hline 6 & $2.71 \pm 0.79$ & $2.73 \pm 0.54$ & 1.69 & $<L O Q$ & $<L O D$ & $<L O D$ & $<L O D$ & $<L O Q$ & $<L O Q$ & $<L O Q$ & 1.20 & 2.30 \\
\hline 7.A & $41.07 \pm 8.49$ & $43.72 \pm 4.88$ & 56.78 & 12.05 & 2.96 & 1.97 & 3.67 & 17.45 & 3.53 & 16.50 & 109.75 & 220.75 \\
\hline 7.B & $10.18 \pm 1.64$ & $9.08 \pm 0.99$ & 16.12 & 2.39 & 0.47 & 0.52 & 0.76 & 2.55 & 0.36 & 4.38 & 94.00 & 192.25 \\
\hline 7.C & $2.99 \pm 0.49$ & $3.07 \pm 0.33$ & 2.42 & 0.65 & $<L O D$ & $<L O Q$ & $<L O Q$ & 0.56 & 1.08 & 0.83 & 23.55 & 56.50 \\
\hline $8 . \mathrm{A}$ & $6.64 \pm 0.72$ & $6.73 \pm 0.84$ & 10.84 & 4.20 & 0.46 & 0.63 & 1.62 & 5.50 & 3.16 & 8.70 & 0.71 & 4.07 \\
\hline 8.B & $1.34 \pm 0.45$ & $1.34 \pm 0.24$ & $<1.10$ & $<L O Q$ & $<L O D$ & $<L O D$ & $<L O D$ & $<L O Q$ & $<L O Q$ & $<L O Q$ & $<L O Q$ & $<\mathrm{LOQ}$ \\
\hline 8.C & $1.41 \pm 0.23$ & $1.41 \pm 0.07$ & $<1.10$ & $<L O Q$ & n.d. & $<L O D$ & $<L O Q$ & 0.54 & 0.47 & 0.48 & $<L O Q$ & $<L O Q$ \\
\hline
\end{tabular}

LOQ: $0.32 \mu \mathrm{g} \mathrm{g}{ }^{-1}$; LOD: $0.08 \mu \mathrm{g} \mathrm{g}^{-1}$; n.d.: not detected 